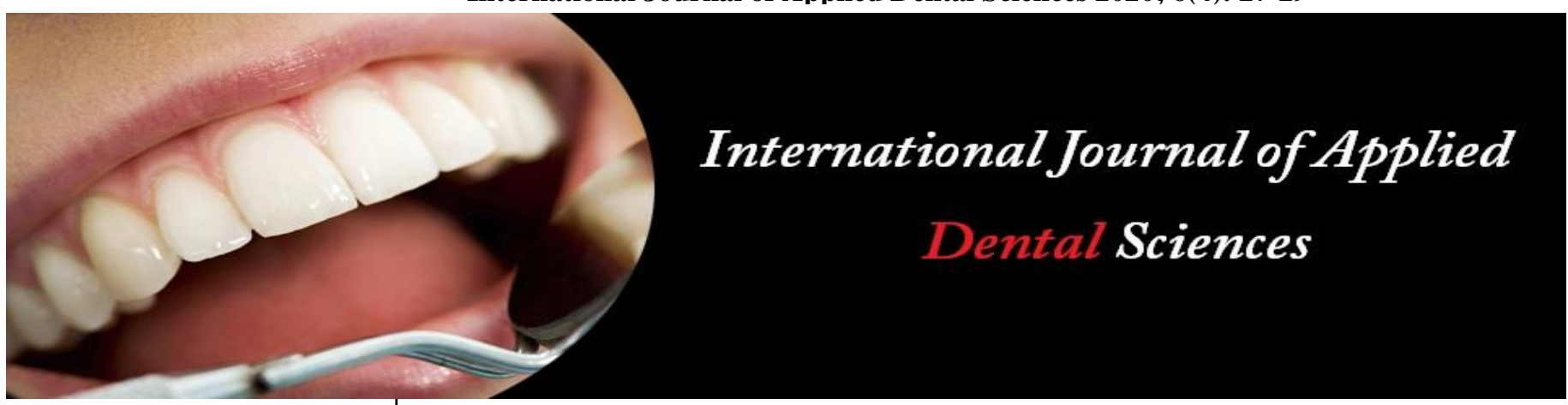

ISSN Print: 2394-7489

ISSN Online: 2394-7497

IJADS 2020; 6(4): 27-29

(C) 2020 IJADS

www.oraljournal.com

Received: 10-08-2020

Accepted: 17-09-2020

Faiqah Lanker

Department of Conservative

Dentistry and Endodontics, The

Oxford Dental College,

Bangalore, Karnataka, India

Nishat M Hussaini

Department of Conservative

Dentistry and Endodontics, The

Oxford Dental College,

Bangalore, Karnataka, India

Corresponding Author:

Faiqah Lanker

Department of Conservative

Dentistry and Endodontics, The

Oxford Dental College,

Bangalore, Karnataka, India

\section{Evaluation of the factors and treatment options of separated endodontic files among practitioners}

\section{Faiqah Lanker and Nishat M Hussaini}

DOI: https://doi.org/10.22271/oral.2020.v6.i4a.1043

\section{Abstract}

Background: The present study was conducted to evaluate the factors and treatment options of separated endodontic files among practitioners.

Materials \& Methods: The present study was conducted among 180 dental practitioners of both genders. A questionnaire was prepared and distributed among practitioners which consisted of information regarding incidence of SEF and behaviour, factors contributing to SEF, treatment options, management mishaps and follow-up and prognosis.

Results: 140 practitioners experienced instrument breakage while 40 did not. 110 practitioners among 180 informed patients regarding breakage. Site of instrument breakage was apical third in 80 , middle third in 40 and coronal third in 20 cases. The difference was significant $(P<0.05)$. The reason for instrument breakage was anatomy of root canal in 30\%, manufacturing defect in $20 \%$, improper use in $25 \%$ and improper access in $25 \%$. In $30 \%$ instruments were left in root canal, in $45 \%$ bypassed and in $25 \%$ removed.

Conclusion: Authors found that separated endodontic instrument lead to failure of the treatment and hence should be removed or bypassed.

Keywords: Instrument breakage, separated endodontic files, coronal third

\section{Introduction}

Accidents might occur during the treatment of the root canal system, such as fracture of instruments, root perforations, and ledge formation, occurrences that increase the risks of failure of the endodontic treatment, since they reduce the effectiveness of the elimination of intracanal microorganisms, mainly of those that are located in inaccessible portions of the root canals ${ }^{[1,2]}$. One of the most unpleasant complications mentioned before is the fracture of instruments, as they are normally caused by cinematic movements wrongly applied on the instruments or by the use of deformed instruments that have lost their capacity of supporting the charge of an operation ${ }^{[3]}$.

The most common causes for SEF are root canal anatomy, improper use, inadequate access, manufacturing defects, limitations in physical properties, and insufficient knowledge about the root canal morphology and its variations ${ }^{[4]}$. Both nickel-titanium (Ni-Ti) hand and rotary files used currently for root canal instrumentation due to their greater flexibility than stainless steel files so they offer distinct clinical advantages in curved root canals. Regardless of the favourable qualities $\mathrm{Ni}-\mathrm{Ti}$ instruments, there has been an unfortunate increase in the occurrence of broken instruments ${ }^{[5]}$. Stainless steel instruments commonly fail by excessive torque while Ni-Ti rotary files usually fracture by torsional stress and cyclic fatigue. Recent technological advancements as ultrasonic and micro tube methods allow easy removal of separated instruments. The dental operating microscope allows clinicians to visualize most broken instruments ${ }^{[6]}$. The present study was conducted to evaluate the factors and treatment options of separated endodontic files among practitioners.

\section{Materials \& Methods}

The present study was conducted in the department of endodontics. It comprised of 180 dental practitioners of both genders. The study was approved from institutional ethical committee. 
All were informed regarding the study and written consent was obtained.

Demographic profile was recorded. A questionnaire was prepared and distributed among practitioners which consisted of information regarding incidence of SEF and behaviour, factors contributing to SEF, treatment options, management

mishaps and follow-up and prognosis. Results were tabulated and subjected to statistical analysis. $\mathrm{P}$ value less than 0.05 was considered significant.

\section{Results}

Table 1: Incidence of SEF and behaviour

\begin{tabular}{|c|c|c|}
\hline Parameters & Number & P value \\
\hline \multicolumn{2}{|c|}{ Instrument breakage } & \multirow{3}{*}{0.01} \\
\hline Yes & 140 & \\
\hline No & 40 & \\
\hline \multicolumn{2}{|c|}{ Informed patient } & \\
\hline Yes & 110 & \multirow{2}{*}{0.01} \\
\hline No & 70 & \\
\hline \multicolumn{2}{|c|}{ Site of files breakage } & \\
\hline Apical third & 80 & \multirow{3}{*}{0.05} \\
\hline Middle & 40 & \\
\hline Coronal & 20 & \\
\hline
\end{tabular}

Table I shows that 140 practitioners experienced instrument breakage while 40 did not. 110 practitioners among 180 informed patients regarding breakage. Site of instrument breakage was apical third in 80, middle third in 40 and coronal third in 20 cases. The difference was significant $(P<$ $0.05)$.

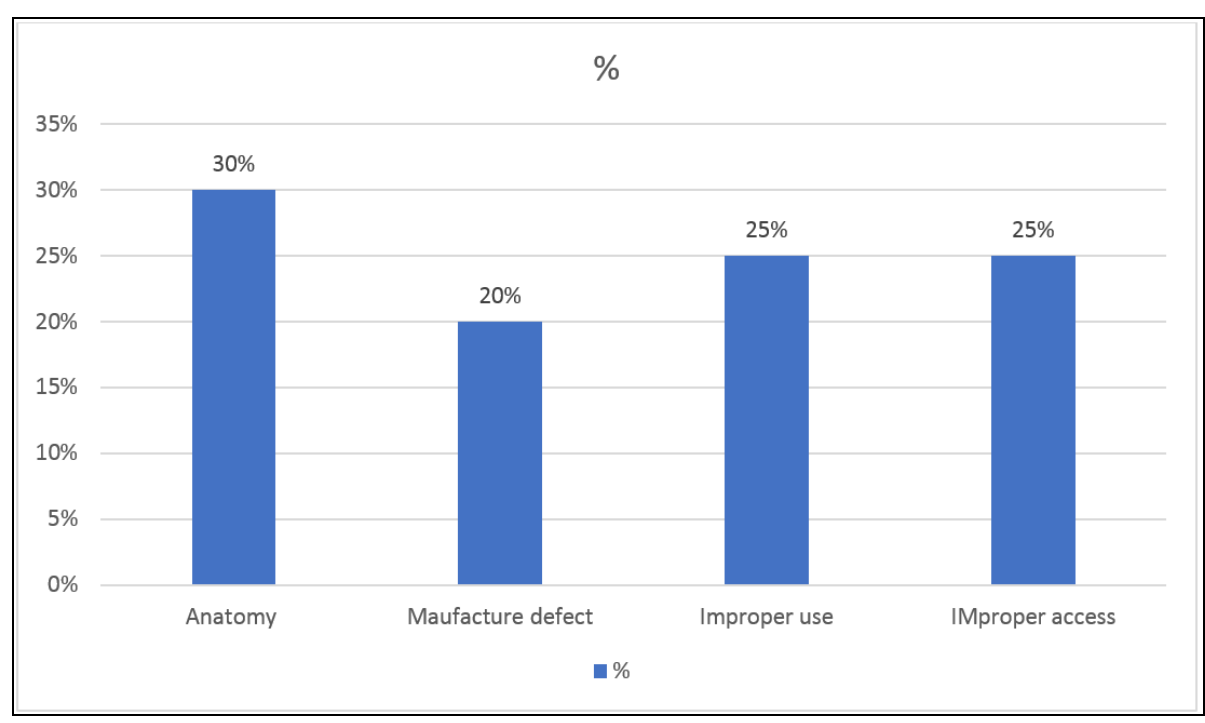

Graph 1: Reason of breakage

Graph I shows that reason for instrument breakage was anatomy of root canal in $30 \%$, manufacturing defect in $20 \%$, improper use in $25 \%$ and improper access in $25 \%$. The difference was non- significant $(P>0.05)$.

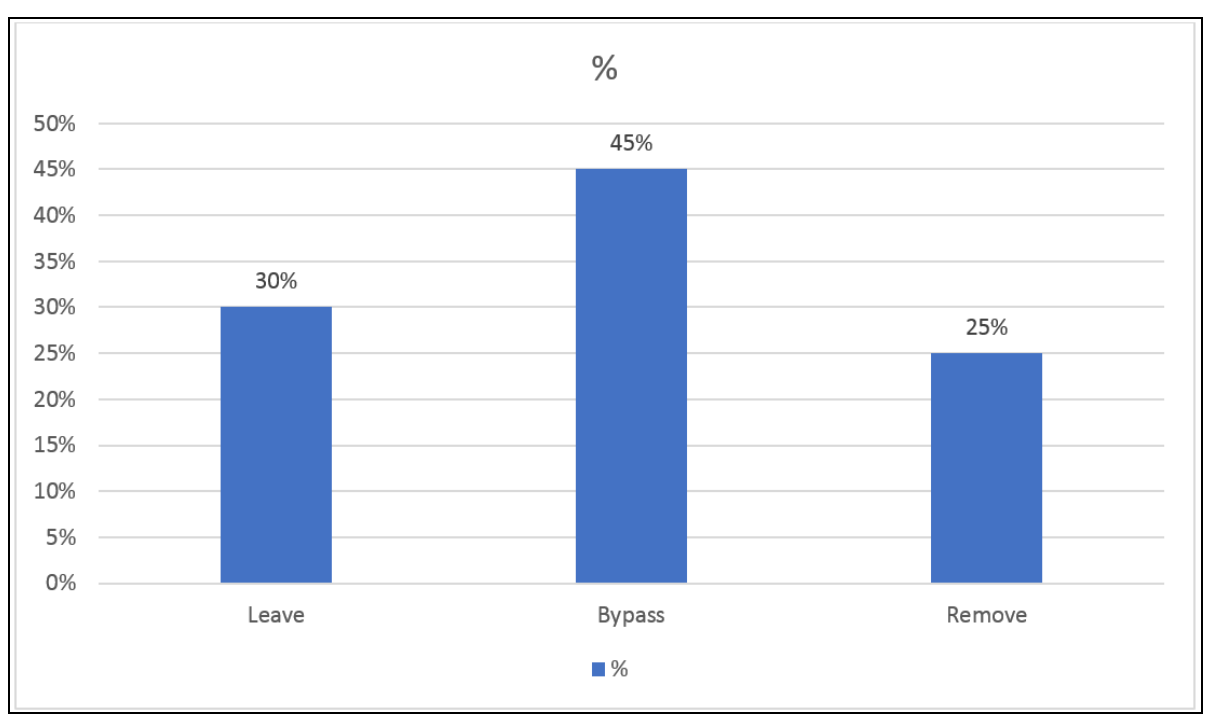

Graph 2: Management of broken instrument 
Graph II shows that in $30 \%$ instruments were left in root canal, in $45 \%$ bypassed and in $25 \%$ removed. The difference was significant $(P<0.05)$.

\section{Discussion}

The existence of a fragment inside the canals requires of the professional a detailed evaluation of the treatment options, immediately after the occurrence, or when planning a retreatment. It is extremely important for the clinician to know the complicating factors when removing a fragment from the root canals ${ }^{[7]}$. They are the anatomy of the root canal system (RCS); the devices available to remove the fragment; the experience and ability of the professional to solve the problem; the localization, size, position, and diameter of the fractured instrument ${ }^{[8]}$. The present study was conducted to evaluate the factors and treatment options of separated endodontic files among practitioners.

We recruited 180 dental practitioners of both genders. We found that 140 practitioners experienced instrument breakage while 40 did not. 110 practitioners among 180 informed patients regarding breakage. Site of instrument breakage was apical third in 80, middle third in 40 and coronal third in 20 cases. Gencoglu and Helvacioglu [9] reported that rotary instruments size \#25.04 were the most fractured rotary instruments at a length of $2.5 \mathrm{~mm}$ because they are the most common MAF size. (73\%) of SEF were in apical third of root canal, $(78 \%)$ of SEF during cleaning and shaping of root canal, $(45 \%)$ of causes of SEF were root canal anatomy and $(66 \%)$ occurred in curved canals. Pedir et al. ${ }^{[10]}$ survery of 35-questionnaire was formulated and e-mailed to all 149 dentists of different dental specialties who are working in different clinical centers. Overall, 118 participants of dentists completed the survey, with response rate of $79 \%$ and the same number of students with response rate of $90.7 \%$. Total of $57.6 \%$ dentists' faced separated files problem during root canal preparation, while only $7.6 \%$ of students faced this problem. $53 \%$ of separated endodontic files (SEF) were hand files, $65 \%$ stainless steel files, $81 \%$ were small size files most common sizes $(\# 15-20)$ ( $p<0.0001)$. Causes of SEF were root Canal anatomy, in $45 \%$. $66 \%$ of SEF occurred in curved canals, $98 \%$ were in molars in mesiobuccal and mesiolingual canals, ( $\mathrm{p}<0.0001$ ). 44\% of SEF were successfully bypassed, $53 \%$ were successfully removed from coronal third of root canal, $42 \%$ of SEF successfully removed using ultrasonics under visualization of operating microscope. $73 \%$ of retained SEF cases showed good prognosis, $(\mathrm{p}<0.0001)$. SEF is a multifactorial clinical problem that must be either removed, by passed to allow complete cleaning, shaping, disinfection, obturation and effective coronal seal.

We found that the reason for instrument breakage was anatomy of root canal in $30 \%$, manufacturing defect in $20 \%$, improper use in $25 \%$ and improper access in $25 \%$. In $30 \%$ instruments were left in root canal, in $45 \%$ bypassed and in $25 \%$ removed. Simon et al. ${ }^{[11]}$ reported that $\mathrm{Ni}-\mathrm{Ti}$ instruments are not more fragile than a stainless steel instrument of equivalent size. Fractured instruments occurred long before the introduction of rotary $\mathrm{Ni}-\mathrm{Ti}$ instruments.

Knowing that the removal of fractured instruments is one of the most difficult procedures in endodontics, but that this choice is essential to the success of the endodontic treatment, it is important to develop or adapt some techniques to facilitate such procedure. Several devices have been created, but none of them is completely effective to be used in all the cases. Moreover, there is no standardized protocol in the literature to be followed when it is necessary to remove a fractured instrument from the root canals ${ }^{[12]}$.

The shortcoming of the study is small sample size.

\section{Conclusion}

Authors found that separated endodontic instrument lead to failure of the treatment and hence should by removed or bypassed.

\section{References}

1. Bonaccorso A, Cantatore G, Condorelli GG, Schäfer E, Tripi TR. Shaping ability of four nickel-titanium rotary instruments in simulated S-shaped canals. J Endod 2009;35:883-86.

2. Hülsmann M, Schinkel I. Influence of several factors on the success or failure of removal of fractured instruments from the root canal. Endod Dent Traumatol 1999;15:25258.

3. Grossman LI. Guidelines for the prevention of fracture of root canal instruments. Oral Surg Oral Med Oral Pathol 1969;28:746-52.

4. Vaudt J, Bitter K, Neumann K, Kielbassa AM. Ex vivo study on root canal instrumentation of two rotary nickel-titanium systems in comparison to stainless steel hand instruments. Int Endod J 2009;42:22-33.

5. Choksi D, Idnani B, Kalaria D, Patel RN. Management of an Intracanal Separated Instrument: A Case Report. Iran Endod J 2013;8:205-07.

6. Soares JA, Brito-Junior M, Silveira FF, Nunes E, Santos SM. Favourable response of an extensive periapical lesion to root canal treatment. J Oral Sci. 2008;50:10711.

7. Öztan MD. Endodontic treatment of teeth associated with a large periapical lesion. Int Endod J 2002;35:73-78.

8. Madarati AA, Watts DC, Qualtrough AJE. Factors contributing to the separation of endodontic files. Br Dent J 2008;204:241-45.

9. Gencoglu N, Helvacioglu D. Comparison of the different techniques to remove fractured endodontic instruments from root canal systems. Eur J Dent 2009;3:90-95.

10. Pedir SS, Mahran AH, Beshr K, Baroudi K. Evaluation of the Factors and Treatment Options of Separated Endodontic Files among dentists and undergraduate students in Riyadh area. Journal of clinical and diagnostic research: JCDR. 2016;10(3):18.

11. Simon S, Machtou P, Tomson P, Adams N, Lumley P. Influence of fractured instruments on the success rate of endodontic treatment. Dent Update 2008;35:172-79.

12. Parashos P, Messer HH. Rotary NiTi instrument fracture and its consequences. J Endod 2006;32:1031-43. 